\title{
Influence Factors of Satisfaction with Mobile Learning APP: An Empirical Analysis of China
}

\author{
https://doi.org/10.3991/ijet.v13i03.8381 \\ Liqiong Liu \\ Wuhan University, Wuhan Business University, Wuhan, China \\ Liyi Zhang \\ Wuhan University, Wuhan, China \\ Pinghao $\mathrm{Ye}^{\left({ }^{凶}\right)}$ \\ Wuhan Business University, Wuhan, China \\ Yezigege1977@163.com \\ Qihua Liu \\ Jiangxi University of Finance and Economics, Nanchang, China
}

\begin{abstract}
The main purpose of this study is to construct the user satisfaction structure model of mobile learning APP (software designed that run on mobile devices) from the perspective of the mobile learning participants, and to analyze the influence factors of satisfaction with mobile learning APP. The results of this study show that perceived responsiveness and perceived content are both the important factors that affect user satisfaction with mobile learning APP. Users have high satisfaction with the content conforming to the mobile learning context. Users expect to get immediate feedback in the process of learning, which can improve the learning methods and efficiency.
\end{abstract}

Keywords-Mobile learning, Influence factors, Consumer behavior, APP, China, Student

\section{Introduction}

With the high-speed development of mobile Internet, smart mobile terminals, such as smartphone, Ipad, tablet, have become college students' study and life necessities [1]. APPs, which are software programs running on mobile devices, have become the important carrier of information and services. APPs refers to the applications on mobile intelligent terminal equipment. Mobile learning APP, which is one kind of APPs, mainly involves the content of study, reading, examination, etc. Mobile learning APP makes it possible for users to study anytime and anywhere via mobile intelligent terminals, which greatly improve the convenience of learning and users' learning enthusiasm. 
According to statistics data of the APP store by December 2014, mobile learning APP has reached 70000, only after the game APP and ranked second in number. Meanwhile, the overall utilization rate of mobile learning APP is $76.1 \%$. More than $70 \%$ of the users used education APP in the past six months. Among the education APP users, $85.8 \%$ of them showed the willingness to continue to use in the future, and $56 \%$ of them expressed the willingness to pay for education APP. Obviously, digital learning is the development trend of school and family education. As a result, the education industry which has a large number of college student users has huge development potential, and learning APP targeted at college students has a broad market in the future.

At present, the mobile APP is on the rise. Language APP [2-5] and examination APP have become the mainly used APP types by college students, however, part of mobile learning APPs still exist some faults, such as boring content, logical confusion and poor manufacture, which were not designed and developed from the perspective of user satisfaction. Whether the learning resources are rich, whether the learning goals can be achieved, whether the APPs need to be paid have become users' mostly concerned factors. Based on the college students' extracurricular learning APP, the research explored the influence factors of college students' satisfaction with extracurricular APP, by analyzing college students' learning habits and cognitive development. It also revealed the specific influence of perceived responsiveness, perceived network and perceived content on college students' satisfaction with the use of mobile learning APP through empirical study. Furthermore, it provided the reference and suggestion to interaction design ideas, principles and methods of mobile learning APP of college students and to improve the user satisfaction with mobile learning APP.

\section{$2 \quad$ Literature review}

The research on the satisfaction of mobile learning is an important issue in the field of user learning behavior. In recent years, with the rapid development of mobile network, most existing literatures focus on the analysis of current situation, service mode and technical implementation of mobile learning, whereas, rarely involve the satisfaction with mobile learning APP. With the wide application of social media, the influence of the integration of mobile APP and social media on students' learning has become a research focus.

\subsection{Mobile learning APP}

The development of mobile technology provides users more chance to receive education. The availability of mobile learning APP helped bridge inequities around access and uses of technology for academic growth and personal empowerment [6]. The rapid popularization and application of $4 \mathrm{G}$ technology increased the number of APP downloaded by users. The faster the network was, the more APPs user could download [7] . Mobile learning could enhance the learning interest and improve the grades $[6,8]$. Studies indicated that Indonesia's teachers had positive perception to mobile 
learning and had high enthusiasm to participate in it [9]. However, the learner were equipped with a number of mobile devices that run by different operating system with diverse device features. To develop cross-platform mobile learning system would receive increased interest [10]. In addition, the developers paid attention to how to improve users' learning efficiency by using mobile learning APP [11], by means of the method of quantitative to analyze the effect of the use of smartphones and APPs by college students, found that mobile learning could bring students more practice chances, not only establishing contact with future career, but also fostering collaborative work among students and professors.

\subsection{Research of mobile learning behavior}

Mobile learning APP could significantly improve the users' ability to understand and solve problems, promoting users' learning initiative [12]. The research on mobile learning behavior provided mobile APP developers personalized learning tools to timely reply and reward the learners, ultimately enhancing the learning efficiency [8]. A large number of literatures studied mobile learning behavior of different groups. [13] investigated mobile learning APP for older people with dementia, and based on the analysis of their learning behavior, explored the development principle of mobile learning APP. Design principle and method to develop mobile learning APP which was suitable for dyslexia children[14]. The smart phone was more helpful than computer to promote students' learning motivation[15], to enhance the frequency of interaction study, to improve the efficiency of preparation before class. That mobile learning APP could support these doctors in access to learning and practice data timely and conveniently, changing their way of resource acquisition[16]. However, they still liked to consult experienced doctor, rather than relied solely on technology because the APP was only a supplement and could not substitute the discussion of the medical team. The effect of Iranian students learning English by using cellphone and that mobile learning is an effective way to improve listening comprehension ability[3]. It was widely believed that cellphone was a very interesting and creative way to learn a new language. It could give more opportunities to learn and the students could listen to their interested topics anywhere and anytime. [17] studied Malaysian graduate students' attitude towards accepting mobile language learning APP. The results showed that this kind of APP could improve the level of language learning. Moreover, faculty members and curriculum design researchers found a way to use cellphones for extracurricular independent interactive learning [18], after comparing the learning effect of the use of mobile electronic dictionary with the use of printed dictionary, presented that the former could significantly improve the language ability. $[2,4]$ verified that using mobile learning APP could increase the students' vocabulary. The effect that employees using mobile APP for informal learning also attracted the attention of the researchers. [19], through case analysis of multiple employees' informal learning, put forward the design principle of mobile learning APP. 


\subsection{Research of mobile learning APP technology}

Some papers studied the development methods and principles of mobile learning APP. Integrating mobile technology and the traditional way is the foundation of mobile learning design. [8, 20], on the basis of the learning habits of the sales department staff, proposed the staff mobile learning APP should include six modules: strategies for streamlining, key concepts, solutions, online course, best practices and manager meeting tool. Mobile learning APP could significantly promote enterprise sale performance. The developers should attach great importance to user satisfaction in the development process of mobile learning APP[21]. At the same time, they should introduce content analysis of user comment into the whole development process as an important tool.

A visual programming software, which could help teachers with no programming experience, learn how to design mobile APP fast under the guide of the peer and support staff. It could help teachers develop APP which can meet the diversity needs of learning and teaching[22]. The function of mobile learning APP was the most important reference when students chose mobile APP[1]. Mobility, participation, integration, perceived barriers, perceived usefulness and use intention would affect user satisfaction. Therefore, APP developers should fully consider these factors to design efficient APP. [23] investigated digital storytelling, and then from the perspective of technology put forward mobile APP development framework whose core model must include five aspects: content area knowledge, digital media, community influence, products and development environment. Combined with the mobile-app-based collaborative learning system, come up with system framework, which could help learners to promote higher-order thinking skills[24]. Based on mobile learning environment analysis, developed and designed a mobile learning management system, which was helpful for users and developers to be more easy to use APP at anytime and anywhere and to reduce the delay phenomena caused by too many clicks[25].

The usability and user satisfaction of 3D talking-head mobile assisted language learning APP for non-native speakers, and analyzed the design principles from six aspects of text, graphic, audio, video, animation and colour are researched by[26] . Taking students and users as the participants of designing mobile learning APP has become a hot topic of teaching designer. [27] proposed the paper prototypes which could attract students and users to attend design.

\section{Research model and hypotheses}

Designing mobile learning APP need to consider the operation logic, interface interaction, content, user experience and many other aspects. For the users, the most intuitive feel is the APP UI and the most useful is the interface interaction. Mobile learning APP should meet the users demand for learning goals, in the meantime, it should strengthen the design of learning experience and learning fun, enhance the interface perception, and promote users trust and use[28]. It is important to ascertain of future users towards mobile learning APP. The perception of the consumer will influence their willingness and readiness to use the system[9]. Economic factors and 
equipment factors are no longer the barriers to participation in mobile learning for teachers. System evaluation on the availability of mobile learning APP has received increased interest from researchers [29]. According to the literature review, considering the representative of the selected indicators and the simplicity of the model, three factors - Responsiveness (PR), Perceived Network (PN) and Perceived Content (PC) were chosen to build model, as shown in figure 1.

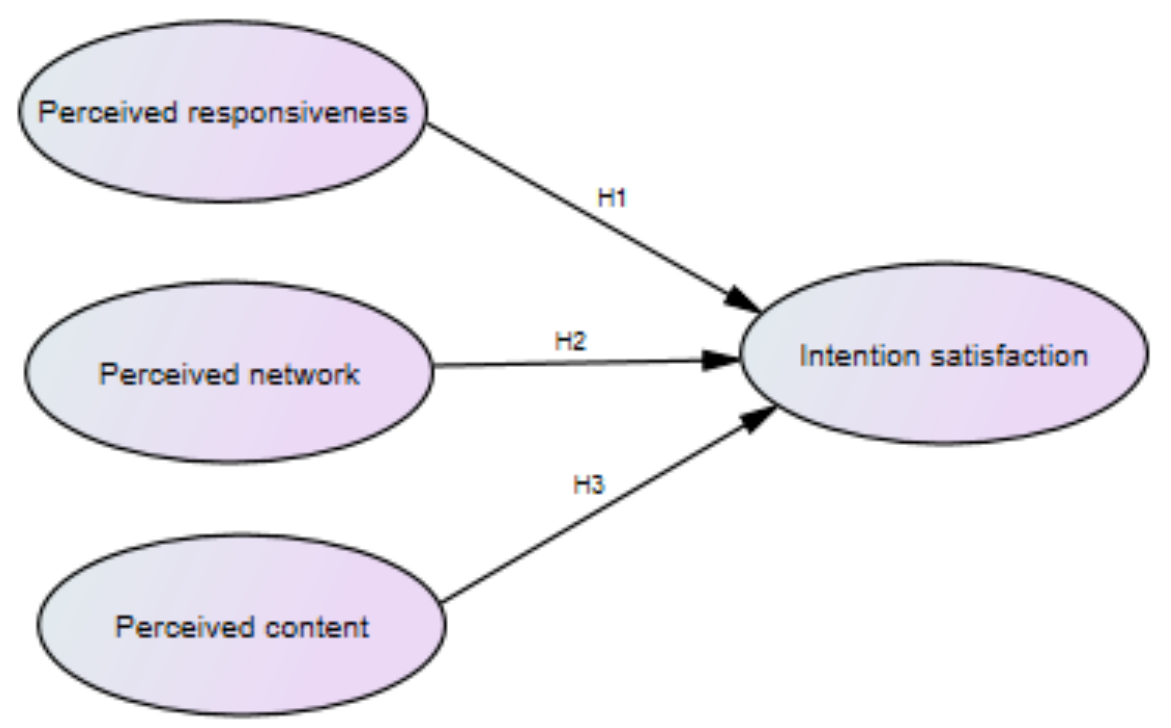

Fig. 1. User satisfaction structure model of mobile learning APP

\subsection{Perceived responsiveness}

Responsiveness is the most important experience in the process of using the APP. Quickly responding to user demand, including providing learning feedback and resources in time, replying timely to user problems encountered in learning, and helping users to test their learning effect, can significantly enhance the users' learning confidence and learning effect[28]. Assessment and feedback are important parts of the teaching and learning [30], Thus, we propose the following hypothesis:

H1. Perceived responsiveness will have a positive effect on the intention satisfaction.

\subsection{Perceived network}

Access to network anytime and anywhere is the important factor that affects user satisfaction when they are using mobile learning APP. Moreover, it depends on the network speed. The users who were continuous to use mobile devices paid more attention to this factor than the ones who stopped using mobile devices[31]. During the period of mobile learning, because two-sides or more-sides communication by use of 
mobile learning APP is mainly informal communication, it required to be carried on anytime and anywhere and to have strong flexibility. It can be considered that good mobile network services will affect users' attitude to use mobile learning APP. Furthermore, access to instant messaging services anytime and anywhere will have a positive influence on the users' adoption attitude. Therefore, the following hypothesis is proposed:

H2. Perceived network will have a positive effect on the intention satisfaction.

\subsection{Perceived content}

Rich graphic elements, reasonable content structure and beautiful interface are all important factors to mobile learning APP. Learning content, including the latest learning materials and the materials occurring in the process of use, is in favor of improving the users' trust in mobile learning APP. Because the learning content is refined and short, it can help learners to use fragmented time to study. Learning content need to fully consider the users' starting point of learning, learning motivation and learning style. Learning content should be pushed according to the users' learning rule and characteristics [32]. Based on these arguments, we propose the following hypothesis:

H3. Perceived content will have a positive effect on the intention satisfaction.

\section{$4 \quad$ Research methodology}

\subsection{Procedure}

The survey collected data by email and online questionnaire. The questionnaires were sent to four university students and staff in Wuhan (China), among which respondents were all mobile learning APP users who have experienced mobile learning APP. The time span of this survey was from September 2014 to December 2014. 468 completed the questionnaire and 428 of them was valid, the effective rate of 85.6 percent. The study used SPSS21.0 as well as AMOS structural equation modeling to analyze.

\subsection{Measures}

The online questionnaire instrument was used for empirical study and every variable was measured by multiple indicators. Measures of the constructs were developed in several stages. In the first stage, based on collecting the existing literature, the research model was constructed and defined. In the second stage, to establish content validity, through the analysis of the scale of existing literature, combined with the application background, the preliminary measurement items were determined. The quotation measurement items were translated accurately to meet the original meaning. In the third stage, to improve the questionnaire, a list of defined research model and measures was submitted to three academics. After they discussed in terms of options, length and expression, the first draft of the questionnaire was formed. Moreover, a 
small-scale interview was hold among 15 users to further modify the measurement items. In the fourth stage, a pretest was conducted among 50 mobile learning users with 45 valid questionnaires back. According to the result of the pretest, the final questionnaire was completed after further simplifying the questionnaire and modifying the problem that terminologies were not explicit, repeated or expression was not clear. All items used five-point scale (1=very strongly disagree, $5=$ very strongly agree). Finally, the large sample questionnaires were released online.

\section{$5 \quad$ Results}

\subsection{Respondents' demographic information}

The sample consisted of 428 respondents. The male/ female ratio of the sample was 48.6 and 51.4 percent, respectively. The demographic information is showed in Table 1. 69.63 percent of respondents were below 20, mainly being concentrated in young group. 69.39 percent of users' education level were above university, mainly college student group. 50.47 percent of respondents used mobile learning APP several times a day, with high use frequency. 41.12 percent of respondents time online every day were about four hours. The analysis figured out that the mobile learning APP has become the dominant form of extracurricular learning, exceptionally for young college students; Mobile learning APP has become a good supplement to the classroom learning.

Table 1. Profile analysis of the investigated sample

\begin{tabular}{|c|c|c|c|}
\hline Measures & Items & Frequency & $\%$ \\
\hline \multirow{2}{*}{ Gender } & Male & 208 & 48.6 \\
\hline & Female & 220 & 51.4 \\
\hline \multirow{5}{*}{ Age } & $\leq 20$ year old & 298 & 69.63 \\
\hline & 21-25 years old & 76 & 17.76 \\
\hline & 26-30 years old & 42 & 9.81 \\
\hline & $31-35$ years old & 7 & 1.64 \\
\hline & $\geqq 36$ years old & 5 & 1.16 \\
\hline \multirow{3}{*}{ Education level } & High School or less & 36 & 8.42 \\
\hline & College & 297 & 69.39 \\
\hline & University or more & 95 & 22.19 \\
\hline \multirow{4}{*}{ Frequency of using mobile learning } & Several times a day & 216 & 50.47 \\
\hline & 2-3 times a week & 99 & 23.13 \\
\hline & 2-3 times a month & 61 & 14.25 \\
\hline & 2-3 times half a year & 52 & 12.15 \\
\hline \multirow{5}{*}{ Times of using the web site very day } & $\leq$ half an hour & 25 & 5.84 \\
\hline & 1 hour & 46 & 10.75 \\
\hline & 2 hours & 97 & 22.66 \\
\hline & 3 hours & 84 & 19.63 \\
\hline & 4 hours & 176 & 41.12 \\
\hline
\end{tabular}




\subsection{Reliability and validity}

To analyze the reliability of the sample data, the reliability and validity test were performed. The results showed that the KMO value was 0.923 which indicated that it was suitable for factor analysis. The Bartlett spherical test value revealed that there was strong correlation between variables, which also showed it was suitable for factor analysis. After using exploratory factor analysis, it could be seen that the overall design of the questionnaire was quite reasonable. Therefore, the results of the validity and reliability test manifested that the data of the research were strong.

Cronbach's $\alpha$ coefficient was used to analyzed the reliability and internal consistency coefficient of the measurement scales. Cronbach's $\alpha$ values show that all variables are higher than 0.7 (from 0.731 to 0.81 ), indicating good reliability. The detailed results are shown in table 2.

Composite reliability values, provided by AMOS, are higher than 0.70 , which display the measured items have good internal consistency. And the reliability of questionnaire is verified. Average variance extracted (AVE) can reflect the convergent validity test. In general, AVE values greater than 0.50 have good convergent validity [33]. It can be found that the AVE values all higher than 0.50 , indicating good convergent validity.

Table 2. Confirmatory factor analysis result

\begin{tabular}{|c|c|c|c|c|c|c|c|}
\hline Construct & Item & Mean & SD & $\begin{array}{c}\text { Factor } \\
\text { loading }\end{array}$ & $\begin{array}{l}\text { Composite } \\
\text { reliability }\end{array}$ & AVE & $\mathbf{a}$ \\
\hline \multirow{3}{*}{ Perceived responsiveness } & PS1 & 2.17 & 0.709 & 0.617 & 0.751 & 0.504 & 0.739 \\
\hline & PS2 & 2.44 & 0.862 & 0.724 & & & \\
\hline & PS3 & 2.51 & 0.924 & 0.779 & & & \\
\hline \multirow{3}{*}{ Perceived network } & PN1 & 2.53 & 0.904 & 0.769 & 0.816 & 0.601 & 0.818 \\
\hline & PN2 & 2.57 & 0.877 & 0.825 & & & \\
\hline & PN3 & 2.64 & 0.917 & 0.729 & & & \\
\hline \multirow{3}{*}{ Perceived content } & PC1 & 2.42 & 0.783 & 0.738 & 0.750 & 0.500 & 0.754 \\
\hline & $\mathrm{PC} 2$ & 2.33 & 0.782 & 0.734 & & & \\
\hline & PC3 & 2.11 & 0.793 & 0.646 & & & \\
\hline \multirow{3}{*}{ Intentiond satisfaction } & IS1 & 2.51 & 0.872 & 0.734 & 0.741 & 0.500 & 0.731 \\
\hline & IS2 & 2.39 & 0.923 & 0.736 & & & \\
\hline & IS3 & 2.16 & 0.830 & 0.622 & & & \\
\hline
\end{tabular}

\subsection{Model estimation and hypothesis testing}

Confirmatory factor analysis was mainly used to test whether the factors accord with the theory put forward by this study, and then to verify the authenticity and accuracy of the theoretical model. In this study, the confirmatory factor analysis adopted the method of structural equation modeling (SEM). And AMOS 7.0 was used to analyze and verify the model. By means of SPSS and AMOS, the estimated values of model path were calculated. The fitting parameter values of the model were presented in table 3 . The $\mathrm{X}^{2} / \mathrm{df}$ ratio (2.879) was below 3 , which was the recommended standard proposed by [34], suggesting a good fit between the data and the theoretical model.

According to the research of [35], three categories of indicators were tested, Absolute Fitting Index $(\mathrm{RMSEA}=0.066, \mathrm{GFI}=0.953)$, Incremental Fitting Index $(\mathrm{NFI}=$ 
$0.951, \mathrm{CFI}=0.967, \mathrm{IFI}=0.968)$ and Parsimony Fitting Index $(\mathrm{PGFI}=0.525, \mathrm{PNFI}=$ $0.620, \mathrm{PCFI}=0.630)$. All indicators met the standard, implying a good fit.

Table 3. Model fit summary for the proposed research model

\begin{tabular}{|l|c|c|}
\hline \multicolumn{1}{|c|}{ Fit index } & Model & Recommendation \\
\hline $\mathrm{P}$ & 0.000 & $<0.001$ \\
\hline $\mathrm{X}^{2} / \mathrm{df}$ & 2.879 & $<3.00$ \\
\hline GFI & 0.953 & $>0.90$ \\
\hline Comparative fit index (CFI) & 0.967 & $>0.90$ \\
\hline Tucker-Lewis index (TLI) & 0.950 & $>0.90$ \\
\hline AGFI & 0.914 & $>0.80$ \\
\hline IFI & 0.968 & $>0.90$ \\
\hline NFI & 0.951 & $>0.90$ \\
\hline RMSEA & 0.066 & $<0.08$ \\
\hline
\end{tabular}

\section{$5.4 \quad$ Results of hypotheses test}

This research adopted maximum likelihood estimation (MLE) to estimate the path coefficients. The results of the hypotheses test are summarized in Table 4. As predicted by $H 1$, perceived responsiveness have a positive effect on the intention satisfaction (C.R. $=4.34, \mathrm{p}<0.001$ ). As predicted by H3, perceived content have a positive effect on the intention satisfaction (C.R. $=3.354, \mathrm{p}<0.001$ ). However, the results don't support $H 2$, because it was not obvious that perceived network have a positive effect on the intention satisfaction (C.R. $=-0.715, \mathrm{p}>0.05)$.

Table 4. Path coefficients and hypotheses test

\begin{tabular}{|c|c|c|c|c|c|}
\hline Hypothesis & Relationship & Coefficients & C.R. & $\boldsymbol{p}$-value & Supported \\
\hline H1 & PS $\rightarrow$ IS & 0.699 & 4.340 & $<0.001$ & Yes \\
\hline H2 & PN $\rightarrow$ IS & -0.067 & -0.715 & $>0.001$ & No \\
\hline H3 & PC $\rightarrow$ IS & 0.388 & 3.354 & $<0.001$ & Yes \\
\hline
\end{tabular}

\section{Discussion}

In this study, we constructed the user satisfaction structure model of mobile learning APP. Through the empirical study, the influence factors of satisfaction with mobile learning APP were analyzed. It is found that perceived responsiveness and perceived content are two major factors in influencing users satisfaction.

As the perceived responsiveness is a important influence factor of satisfaction, the mobile learning APP developers could take the interaction into consider. Firstly, using wireless network can help users to share at anytime and anywhere. Secondly, especially with the use of social networks, a lot of social APPs have been embedded in mobile learning environment. Using the public platform, pushing message and other functions can set up the interaction platform between students and students, teachers and students, increasing the interaction efficiency and promoting meaningful learning. Lastly, establishing a comprehensive, dynamic and diversified evaluation mechanism is beneficial to the result evaluation between the users. Users can evaluate 
other people' learning dynamic, sharing resources, uploading task and completing results. Users can mutually evaluate by comment and instant communication, which makes it possible for users to timely correct problems and find the solutions to further improve the learning process and enhance the learning effect.

Perceived content could enhance satisfaction if it can meet the users' needs and even above their expectation. The fun element should be added to attract users to participate in study. The developers need to decide learning content according to the users' learning rule and characteristics. The design of learning activity should combine the teaching content, for example, preview before class and review after class could be put into mobile learning APP, which can let users independently study. Learning content should be short and refining, making it easy for users to use fragmented time to study.

\section{Conclusion}

\subsection{Managerial implications}

When users apply mobile learning APP, the learning environment is complex and there are many interference factors, which will distract the learners' attention. In the study, responsiveness has become one of the important factors affecting user satisfaction. The developers should provide adaptive content or feedback according to different user model, provide appropriate learning evaluation for learners to understand learning process and effect, provide evaluation approach to meet the mobile learning context. Mobile learning content has become a factor that influence the use of mobile learning APP. Therefore, the APP knowledge should base on being short, concise and refined when the APP developers design the learning content. The user can complete a full content unit in limited time. So APP content should be clear, reasonable and convenient to search.

Mobile learning APP developers should pay more attention to practice. They may develop mobile learning APP with systematic function on the widely used mobile intelligent terminal platform, which can provide flexible and convenient way of daily learning. Interaction function of extracurricular learning APP should be pertinent, educational, enjoy, playful, simple and safe. Some technologies, such as context awareness, RFID, and virtual reality, can be used in the process of development. And then, that can create a seamlessly full-featured environment and offer the corresponding learning strategies and tools to help college students adapt to the complex environment, making mobile learning truly happen.

\subsection{Limitations and future research}

The advantages of mobile learning APP are augmented reality, simulations, immediate feedback, and the ability to record and the capture data [8]. With the rapid development of the wireless network technology and intelligent terminals, mobile learning has become a beneficial supplement of formal learning. User satisfaction with 
mobile learning APP is influenced by several factors, such as uncontrollability of learners' attention, and the limitation of technical function, etc.. Although this study empirically researched the factors influencing user satisfaction with the use of mobile learning APP, and pointed out the matters needing attention, it didn't comprehensively analyze the factors, for example, price and privacy protection were not included in the analysis framework. Future research could focus on the efficiency or privacy protection of mobile learning APP.

\section{Acknowledgment}

This study was supported by the China Scholarship Council (201408420159) ; Humanities and Social Science research project in Hubei province department of education (13g587and14Z073) and Hubei province university excellent young and middle-aged scientific and technological innovation team plan (T201730).

\section{References}

[1] D. Yunfei.(2015). Information use and barries on a mobile app in diatance learning. Journal of Library and Information Services in Distance learning, 9(3): 204-220. https://doi.org/10.1080/1533290X.2015.1052608

[2] R.-C. Shih, C. Lee, and T.-F. Cheng.(2015). Effects of English Spelling Learning Experience through a Mobile LINE APP for College Students. Procedia - Social and Behavioral Sciences, 174(1): 2634-2638. https://doi.org/10.1016/j.sbspro.2015.01.945

[3] A. S. Azar and H. Nasiri.(2014). Learners' Attitudes toward the Effectiveness of Mobile Assisted Language Learning (MALL) in L2 Listening Comprehension. Procedia - Social and Behavioral Sciences, 98(1): 1836-1843. https://doi.org/10.1016/j.sbspro.2014.03.613

[4] R. K. Agca and S. Özdemir.(2013). Foreign Language Vocabulary Learning with Mobile Technologies. Procedia - Social and Behavioral Sciences, 83(1): 781-785. https://doi.org/10.1016/j.sbspro.2013.06.147

[5] R. Jennifer and S.-C. Denise.(2011). The potential for building high-school sthdents' vocabulary using an ipod touch and gaming app. Journal of open, flexible, and distance learning, 15(2): 55-67.

[6] C. Mouza and T. Barrett-Greenly.(2015). Bridging the app gap: An examination of a professional development initiative on mobile learning in urban schools. Computers \& Education, 88(10): 1-14. https://doi.org/10.1016/j.compedu.2015.04.009

[7] S. Chung.(2014). An empirical analysis of usage dynamics in a mobile music app: evidence from large-scale data. Internet Research, 24(4): 436-456. https://doi.org/10.1108/Int R-05-2013-0088

[8] T. Hetrick.(2015). Book review of The new landscape of mobile learning: Redesigning education in an app-based world. Open Praxis, 7(1): 113-115. https://doi.org/10.5944/open praxis.7.1.178

[9] I. K. Yusri, R. Goodwin, and C. Mooney.(2015). Teachers and Mobile Learning Perception: Towards a Conceptual Model of Mobile Learning for Training. Procedia - Social and Behavioral Sciences, 176(1): 425-430. https://doi.org/10.1016/j.sbspro.2015.01.492

[10] N. Litayem, B. Dhupia, and S. Rubab.(2015). Review of Cross Platforms for Mobile Learning Application Development. International Journal of Advanced Computer Science and Applications, 6(1): 31-39. https://doi.org/10.14569/IJACSA.2015.060105 
[11] E. VÁZquez-Cano.(2014). Mobile Distance Learning with Smartphones and Apps in Higher Education. Educational Sciences: Theory \& Practice, 14(4): 1505-1520.

[12] D. Sonal, X. Xin, and T. M. Yin.(2013). Mobile app development to increase student engagement and problem solving skills. Journal of information systems education, 24(4): 299-308.

[13] K. Pitts, K. Pudney, K. Zachos, N. Maiden, B. Krogstie, S. Jones, et al.(2015). Using mobile devices and apps to support reflective learning about older people with dementia. Behaviour \& Information Technology, 34(6): 613-631. https://doi.org/10.1080/0144929X.20 15.1015165

[14] R. Skiada, E. Soroniati, A. Gardeli, and D. Zissis.(2014). EasyLexia: A Mobile Application for Children with Learning Difficulties. Procedia Computer Science, 27(1): 218-228. https://doi.org/10.1016/j.procs.2014.02.025

[15] M. K. Lee.(2015). Effects of mobile phone-based app learning compared to computerbased web learning on nursing students: pilot randomized controlled trial. Healthc Inform Res, 21(2): 125-33. https://doi.org/10.4258/hir.2015.21.2.125

[16] A. Bullock, R. Dimond, K. Webb, J. Lovatt, W. Hardyman, and M. Stacey.(2015). How a mobile app supports the learning and practice of newly qualified doctors in the UK: an intervention study. BMC Med Educ, 71(15): 1-6. https://doi.org/10.1186/s12909-015-0356-8

[17] E. Soleimani, K. Ismail, and R. Mustaffa.(2014). The Acceptance of Mobile Assisted Language Learning (MALL) among Post Graduate ESL Students in UKM. Procedia - Social and Behavioral Sciences, 118(1): 457-462. https://doi.org/10.1016/j.sbspro.2014.02.062

[18] M. Rahimi and S. S. Miri.(2014). The Impact of Mobile Dictionary Use on Language Learning. Procedia - Social and Behavioral Sciences, 98(1): 1469-1474. https://doi.org/10.1016/j.sbspro.2014.03.567

[19] G. Jia, C. Daniel, and L. Jie.(2014). Mobile Web 2.0 in the Workplace: A Case Study of Employees' Informal Learning. British Journal of Educational Technology, 45(6): 10491059. https://doi.org/10.1111/bjet.12179

[20] C. Tate.(2013). Mobile masters:to encourage knowledge retention and behavior change in a saleforce, working simply converted its trademark productivity program into a custom mobile learning app. TD: Talent Development, 67(4): 22-24.

[21] E. Platzer and O. Petrovic.(2011). Learning Mobile App Design from user review analysis. International Journal of Interactive Mobile Technologies, 5(3): 43-50. https://doi.org/10.3991/ijim.v5i3.1673

[22] Y.-C. Hsu and Y.-H. Ching.(2013). Mobile App Design for Teaching and Learning: Educators' Experience in an online graduate course. International review of research in open and distance learning, 14(4): 117-139. https://doi.org/10.19173/irrodl.v14i4.1542

[23] C. C. M and A. Marion.(2014). Digital stroytelling as an instrument of learning: Storytelling as a primary form of communicative learning through mobile app books. International Journal of the book, 11(2): 23-33.

[24] C. Cheong, v. bruno, and f. cheong.(2012). Designing a mobile -app -based collaborative learning system. Journal of information rechnology education: innovations in prantice, 11(1): 97-119.

[25] S. Lee.(2015). Design and Analysis of Mobile Learning Management System based on Web App. International Journal of Multimedia and Ubiquitous Engineering, 10(1): 417428. https://doi.org/10.14257/ijmue.2015.10.1.38

[26] K. Segaran, A. Z. M. Ali, and T. W. Hoe.(2014). Usability and User Satisfaction of 3D Talking-head Mobile Assisted Language Learning (MALL) App for Non-native Speakers. Procedia - Social and Behavioral Sciences, 131(1): 4-10. https://doi.org/10.1016/j.sbspro.2 014.04 .069

[27] I. Maya, M. Matthew, B. J. D, and S. Wenonoa.(2013). Fifth graders as app designers : how diverse learners conceptualize educational apps. Journal of research on technology in education, 46(1): 53-80 https://doi.org/10.1080/15391523.2013.10782613 
[28] F. Bo and Y. Ben-cheng.(2015). Research on the design of learning APP for mobile terminal equipment. Computer knowledge and technology, 11(3): 15-16.

[29] A. All, E. P. Nuñez Castellar, and J. Van Looy.(2015). Towards a conceptual framework for assessing the effectiveness of digital game-based learning. Computers \& Education, 88(10): 29-37. https://doi.org/10.1016/j.compedu.2015.04.012

[30] N. D. Pacheco-Venegas, G. López, and M. Andrade-Aréchiga.(2015). Conceptualization, development and implementation of a web-based system for automatic evaluation of mathematical expressions. Computers \& Education, 88(10): 15-28. https://doi.org/10.1016/ j.compedu.2015.03.021

[31] M. Parthasarathy and A. Bhattacherjee.(1998). Understanding post adoption behavior in the context of online service. Information systems research, 9(4): 362-379. https://doi.org/10.1287/isre.9.4.362

[32] W. Shurui.(2014). The review of education APP. Journal of educational instidute of jilin procince, 30(5): 103-104.

[33] C. Fornell and D. F. Larcker.(1981). Evaluating structural equation models with unobservable variables and measurement err. Journal of marketing research, 18(1): 39-50. https://doi.org/10.2307/3151312

[34] W. W. Chin and P. A. Todd.(1995). On the use,usefulness, and ease of use of structural equation modeling in MIS research: a note of caution. MIS Quarterly, 19(2): 237-246. https://doi.org/10.2307/249690

[35] R. Bagozzi and Y. Yi.(1988). On the evaluation of structural equation models. Journal of the academy of marketing science, 16(1): 74-94. https://doi.org/10.1007/BF02723327

\section{Authors}

Liqiong Liu is a doctoral student at the School of Information Management, Wuhan University, and an associate professor at the School of Business Administration, Wuhan Business University, Wuhan, 430056, China.

Liyi Zhang is a professor at the School of Information Management, Wuhan University, Wuhan, 430072, China.

Pinghao YE is an associate professor at the School of Information Engineering, Wuhan Business University, Wuhan, 430056, China.

Qihua Liu is an associate professor at the School of Information Management, Jiangxi University of Finance and Economics, Nanchang, 330013, China.

Article submitted 07 February 2018. Final acceptance 23 February 2018. Final version published as submitted by the author. 